\title{
Open Access Revolution: Is it a paradigm shift of scholarly publishing practices? A literature review of global scenario
}

\author{
Mohamed Majeed Mashroofa ${ }^{1}$
}

\begin{abstract}
This paper aims to provide an overview of open access and its consequences. This focuses especially on open access for scholarly publishing. This is a review of literature, describing the evolution of open access, recent trend and its growth and adoption at global level. Findings of this study are the philosophy of open access has tremendously grown in all over the globe since 2002 and the benefits have leaded the researchers to alter their practices of scholarly communication. Even the research funders and institutions have mandated open access for the dissemination of research findings for which they grant financial assistance. Limited literature regarding open access status in Sri Lanka indicates that there is room for improvement. This paper proposes the Sri Lankan scientists, to adopt open access for scholarly communication practices to maximize visibility and to earn high impact for their research. Similarly, funding agencies, universities and research institutions can formulate open access policy, establish institutional repositories, and motivate publishing in open access journals and archiving in digital repositories for future development and research. Also, this will help librarians to make a strategic decision to develop open science. This study recommends the researchers in Sri Lanka to do an explorative study to identify the local scenario.
\end{abstract}

Key words: Open Science, Open Knowledge, Open Access, Business Models of Journals, Scholarly Publishing

\section{Introduction}

The word 'open' means unlocking or disclosing. Open education, open science, open knowledge and open access are the phrases born by unlocking concept or breaking the barriers related to the particular issue. Open science is the movement to make scientific research, data and dissemination accessible to all levels of an inquiring society, amateur or professional. Similarly open knowledge is knowledge that one is free to use, reuse, and redistribute without

\footnotetext{
${ }^{1}$ Senior Assistant Librarian, South Eastern University of Sri Lanka. E- mail: mashroof@seu.ac.lk
} 
legal, social or technological restriction. Openness in each and every perspective has created innovative approaches. Digital technologies and their rapid development in capacity are the key drivers of open science. Some called as 'open research' or 'open scholarship'. European Union (2015) says open science is formerly known as Science 2.0., which was described "as the ongoing evolution in the modus operandi of doing research and organizing science. These changes in the dynamic of Science and doing research are enabled by digital technologies and driven by globalization of the scientific community, as well as the need to address the grand challenges of our times. They have an impact on the entire research cycle from the inception of research to its publication, as well as the way in which the cycle is organized". This can be simply explained as science is in transition now and it is more transparent and effective. Research practices are also in transition due to the rapid development of technology and globalization. Open Science encompasses open source, open code, open access, open online courses (MOOCs), text and data mining, scholarly communication and assessing the impact. Open science is very important in the basis of open innovation. Horizon 2020 makes open access as mandatory for research carried out by using research grant. In this project 'open science has been included in the "Science with and for society". Mayer (2015) mentioned that the term open science shows a broadening picture, covering all potentials of the openness paradigm. Open sciences is a consequent of open access which encompasses some more aspects.

The elements, norms, values, boundaries and the related scientific terms to open science have broad scope, but this study is limited only on 'Open Access' perspectives. Because, at present only some prototypes are in use in many countries especially in developing nations. Though it is important to enter the world of data, as beginners we have to do a lot towards developing open access first.

Open Access is a growing international movement that uses the Internet to open the locked doors that once hid knowledge which is closely related with open education, open science and open knowledge. Open access has been given many definitions. Suber (2004) defines as "Open Access (OA) literature is digital, online, free of charge and free of most copyright and licensing 
restrictions. What make it possible are the internet and the consent of the author or copyright-holder". Open access resources include Open Educational Resources (OER) and scientific publications such as open access books and journals. The level of availability of OER and OA publications foster the development of the information society. There is a relationship between OER and OA scientific publications with lifelong learning or continuous learning. The very basic idea of OA scientific publications is breaking access barriers mainly by subscription cost. It gives readers to make use of relevant literature without payment. It gives authors and their works high visibility, readership and research impact in terms of citations (Swan, A. (2012), (Harnard \& Brody, (2004), Eysenbach, (2006), Koler-Povh et al. (2012)). The benefits are reciprocal in case of authors and readers. Scientific communities such as academia, researchers and scientists, teachers, students and even members of general public have the rights to use and re-use open access information. In addition this encourage the unrestricted sharing of research results with everyone.

Open Access resources can be categorized as online resources and web based resources. Open access literature is available in open access journals, open access books, Institutional Repositories (IR), and digital archives and so on. OA journals are mainly peer reviewed and contain scholarly information. It is obvious that nowadays academics have a trend in publishing their research papers in OA journals and using OA literature to carryout research.

\section{Open Access Movements}

Open Access movements started around the globe since 2002. The aim of the open access movement is mainly to consider information protection of authors. Protection of authors' rights is important in OA. Budapest Open Access Initiatives was published in February, 2002 which includes two important recommendations. To achieve open access scholarly journal literature they had identified two strategies; the first one is self-archiving through which authors can deposit their publications of peer reviewed journals in any electronic archives and the second strategy is open access journals. Scholars have to launch open access journals as new publishing revenue and to elect open access as a transition mode for existing journals, too. Budapest Open Access Initiatives in 2002 proclaimed that OA means free availability 
of literature on the public internet, permitting any users to read, download, copy, distribute, print, search, or link to the full texts of these articles, crawl them for indexing, pass them as data to software, or use them for any other lawful purpose, without financial, legal, or technical barriers other than those inseparable from gaining access to the internet itself. The only constraint on reproduction and distribution, and the only role for copyright in this domain, should be to give authors control over the integrity of their work and the right to be properly acknowledged and cited.

Following that, Bethesda statements on Open Access Publishing was released in June 2003. The purpose of this document is to stimulate discussion within the biomedical research community on how to proceed, as rapidly as possible, to the widely held goal of providing open access to the primary scientific literature. This document has four sections and the first is definition of open access publications. An Open Access Publication is one that meets the following two conditions:

1. "The author(s) and copyright holder(s) grant(s) to all users a free, irrevocable, worldwide, perpetual right of access to, and a license to copy, use, distribute, transmit and display the work publicly and to make and distribute derivative works, in any digital medium for any responsible purpose, subject to proper attribution of authorship [2], as well as the right to make small numbers of printed copies for their personal use".

2. "A complete version of the work and all supplemental materials, including a copy of the permission as stated above, in a suitable standard electronic format is deposited immediately upon initial publication in at least one online repository that is supported by an academic institution, scholarly society, government agency, or other well-established organization that seeks to enable open access, unrestricted distribution, interoperability, and long-term archiving (for the biomedical sciences, PubMed Central is such a repository)."

They added notes as open access is a property of individual works, not necessarily journals or publishers and community standards, rather than copyright law, will continue to provide the mechanism for enforcement of proper attribution and responsible use of the published work, as they do now. 
In addition this document includes statements for institutions and funding agencies, statements for libraries and publishing working group and statements for scientists and scientific societies working group.

Berlin Declaration on Open access to knowledge were produced in October 2003. Berlin Declaration (2003) stated as follows that "our mission of disseminating knowledge is only half complete if the information is not made widely and readily available to society". Berlin declaration (2003) defines Open access as a comprehensive source of human knowledge and cultural heritage. Establishing open access as a worthwhile procedure ideally requires the active commitment of each and every individual producer of scientific knowledge and holder of cultural heritage. Open access contributions include original scientific research results, raw data and metadata, source materials, digital representations of pictorial and graphical materials and scholarly materials. In the Berlin Declaration it was decided that open access publication should satisfy two conditions. The two conditions for OA in Berlin Declarations are mentioned below.

1. The author(s) and copyright holder(s) grant(s) to all users a free, irrevocable, worldwide, perpetual right of access to, and a license to copy, use, distribute, transmit and display the work publicly and to make and distribute derivative works, in any digital medium for any responsible purpose, subject to proper attribution of authorship, as well as the right to make small numbers of printed copies for their personal use.

2. A complete version of the work and all supplemental materials, including a copy of the permission as stated above, in a suitable standard electronic format is deposited immediately upon initial publication in at least one online repository that is supported by an academic institution, scholarly society, government agency, or other well-established organization that seeks to enable open access, unrestricted distribution, interoperability, and long-term archiving.

These two conditions are clearly expressed about using OA publications and archiving materials for OA. Apart from OA journals; Berlin Declaration identified some other sources such as raw data, metadata, material sources, 
pictorial and graphical and scholarly multimedia materials should be provided freely as open access. Since then the importance of open access was aware and practiced elsewhere in the world.

International Federation of Library Associations and Institutions (IFLA) 2003 affirmed that,

"Comprehensive open access to scholarly literature and research documentation is vital to the understanding of our world and to the identification of solutions to the global challenges and particularly the reduction of information inequality". In addition it indicates that "open access guarantees the integrity of the system of scholarly communication by ensuring that all research and scholarship will be available in the perpetuity for unrestricted examination and, where relevant, elaboration or refutation".

(IFLA) 2003 declared at the Glasgow declaration on Libraries and information services and intellectual Freedom that both access and express information without restriction is fundamental right of human beings. In addition IFLA requested all involved in scientific communications including authors, editors, publishers, libraries and institutions in the world to follow open access principles in order to ensure the widest possible availability of scholarly literature and research documentation.

But, researchers have still dilemma whether OA literature is peer review and worthwhile to publish their research papers. OA contains two types of materials. The first one is open access journals. They are compatible with other peer reviewed journals and are called as 'Gold Open Access'. The second is OA archives or IRs which contain preprints, post prints, monographs and unpublished materials. Some literature in archives and Institutional Repositories are not undergone peer review process and these are pre-prints and grey literature. They are known as Green open access. The main purpose of the archives and IRs are simply making their contents freely available to the entire world. 


\section{Quality of Open Access Journals}

Quality of journal is the most important factor concern by authors to publish. This is generally counted by a quantitative measurement known as impact factor. Journals which have high impact factor are recognized as good quality. Impact factor is calculated by number of articles for a particular journal of a year is divided by number of citations received by the same journal for the following year, Lancaster (1991). Apart from the impact factor, peer review process, structure of articles and contents also determine the quality. Open access journals are also peer review. Kenneway (2011) stated that authors are concern with cost and quality. Peer review is extremely emotive topic in the world of scholarly communication. OA publishers also need to be clear in the process of peer review to maintain the quality of journal papers. Majority open access journals are peer reviewed. However there are some ambiguous in this respect prevails among the authors. Scholars' perceptions were examined under reputation, quality, availability and relevance of OA journals by Park and Kin (2007). These four factors concern to scholars and make many of them hesitate to choose OA journals as their main publishing venue. Because, there is misunderstandings and distrust of OA journals among scholars. This may give less weight to articles of open access journals.

Medical journals are ranked by their impact factor. Journals are grouped as tier one journals, tier two journals, tier three journals and tier four journals based on their impact factor. Some tier one medical journals have high impact factor than Science and Nature. For example, New England Journal of Medicine (NEJM) has an impact factor 53 and Journal of the American Medical Association (JAMA) has 30. They give free access to all the articles published in the journal after an embargo period, no publication charge is obtained. Similarly there are many more high impact factor open access and hybrid model journals are available.

Quality of journals depends on the peer-review process, too. This may be single blind review or double blind review. In single blind review, the reviewers are known the identity of the author but the author does not know the reviewer. In the later both reviewer and authors do not aware each other's identity. Publishing in a peer reviewed journal is the most preferable mode of 
communicating research findings as this certifies the quality. Majority open access journals are peer-review.

\section{Technical Characteristics of Open Access Publications}

OA whether it is gold route or green route they have to adopt important technical issues. Mainly they should maintain standards such as Open Archive Initiatives (OAI), interoperability etc. Their formats and architecture must be compatible. And they should have the policy which can be benefitted for both author/s and reader/s.

Open Archive Initiatives (OAI) has implied the importance of interoperability of repositories in order to maintain a standard of all repositories. Open Archive Initiative Protocol for Metadata Harvesting (OAI-PMH) was developed to facilitate deposit and discovery of e-publications found around the world in different subject based repositories and institutional repositories (Pinfield, 2014).

Based on these standards, there are many more software/s were developed such as E-print Repository Software, D-space, Digital Commons, OPUS, Fedora Commons and Green Stone. Dura Space is the main driver for both DSpace and Fedora Commons. Based on Dura Space some more software are also developed for digital preservation and archiving purposes. Some software and the developers have been listed as follows:

Table 1: Repository software and the developers

\begin{tabular}{|l|l|}
\hline Software & Developer/s \\
\hline E-print Repository Software & University of Southampton \\
\hline D-space & Massachusets Inst. of Technology \\
\hline Digital Commons & University of California \\
\hline OPUS & Stutgart \\
\hline Green Stone & Waikato, New Zealand \\
\hline Fedora Commons & Cornell University \\
\hline
\end{tabular}

Greenstone software was incorporated by UNESCO. Open Access and Open Archives are sometimes misinterpreted as same. But these two are different; the latter is based on interoperability of sites and harvest of metadata while the main focus of OA is free of charge or freely accessible. Major institutional repositories in Sri Lanka are created by using D-Space. 


\section{Business Models of Journals}

Digital communication has changed the way of delivery of scholarly research findings from print to electronic, but the process of scholarly publishing and structure of a scientific paper or research paper has not changed. Scholarly publishing process includes editorial review and peer review which remains same as it was to the traditional print journal. However, considerable change is observed in the business model, the way that the users are accessing information. Business models depend on how OA is delivered. Expenses consist of peer review, manuscript preparation and server space. They consider only the production costs. They may charge a processing fee on accepted articles to be paid by the author or author's sponsor (employer, funding agency).

Journals based on subscription have the revenue to generate funds and the development and sustainability has no doubts. However, open access journals have to find some other funding source other than the subscription fee. They are in a position to construct different business models in order to bare the publishing cost and maintain the sustainability. Prosser, David. C. (2013) stated that open access will become the dominant business model for scholarly journals in the internet age". The following models are adopted by journal publishers.

1. Subscription Model: Annual subscription fee is remitted in advance to access the journal whether it is print or electronic. Universities and research institutions spend. Libraries subscribe for print journals and pay a surcharge to get access to the electronic version of the particular journal for which they subscribed for.

2. Big Deal: Big deal is a new business model. Libraries purchase electronic access to a publisher's entire papers rather than selected titles. This is now very popular as this supports for literature survey by providing latest as well as back issues of journals. This business model is known as "Big Deal". This can be done through consortia, too.

3. Toll-access: Particular articles of a journal or database can be purchased online for a specific fee. No need to subscribe for the whole journal. This is known as toll-access. 
4. Author-Payee Model: A fee is paid by the author, institution or sponsor as publishing cost. This is

usually for article processing and known as article processing charge (APC).

5. Payments through Professional membership: Some society journal publishers use fund which is collected from membership fee. This is known as Institutional Membership scheme. Some society journal publishers use membership fee for the expenses of publishing their journals.

6. Public or State funding: Some journals are sustained with public funding and which may be available for free access.

7. Advertising revenue: Some journals bear the cost through advertising and revenue and provide the articles or whole journal free of charge.

8. Collaborative purchasing model: Some organizations and institutions collaboratively fund or sponsor the publishers and the journals published by the particular publisher are made openly available. For instance, SCOAP3 (Sponsoring Consortium for OA publishing in Particle Physics).

9. Institutional Subsidy: Some university press or the libraries publish journals from their own allocation and give it for open access. This is like community publishing. This model is used to publish journal for a niche of small area which selects open source open journal system for publishing. Generally they streamline by the use of dedicating journal production system. Universities and institutions use this model and the expenditures incurred by publishing are of the parent body.

10. Hardcopy sale: Some publishers bear the expenditures by selling hardcopy while the soft copies are available freely. For example, British Medical Journal.

Bennett (2013) p.107 in eds. Shorley \& Jub (2013) stated " now a days there is a general acceptance of Open Access by the majority of publishers and most have initiated some sort of open access model in their existing journal programme". Some reputed publishers follow hybrid model. Those are American Institute of Physics, Nature Publishing Group, British Medical Journal Group, SAGE publisher in the Social Sciences, Springer and Wiley Blackwell. 
Davis (2012) in Kiley (2013) Eds. Shorley \& Jub (2013) in future of Scholarly communication stated that OA articles are $95 \%$ more downloaded than the articles not freely available. OA reduces overall cost of scholarly communication. Research Information Network of UK suggested in 2011 that "significant shift towards Gold OA -the system under which journals are funded by author side charges rather than by subscriptions-has the potential to achieve a high benefit to cost ratio and reduce the UK's net costs for scholarly communication."

On the other hand, Kenneway (2011) has carried out a qualitative research on "author attitudes towards open access publishing" on behalf of an open access publisher known as "INTECH". This study evaluated the attitudes of authors on publishing in OA was tested under three categories. Those are open access improve access to knowledge, author payment and quality. In this study an author has mentioned that,

"I was invited to write a chapter for In Tech on Nanotechnology recently. I initially accepted the offer but then found out that you expect each author to pay.... to do this. I think this approach is fraudulent so I reversed my decision and decided not to publish with In Tech for this reason."

This is clearly indicates that decision of publishing in Open Access Journals is influenced by the cost, that is author-payee model.

Harley (2013) mentioned that crisis on scholarly communication is not accepted by the faculty members. Faculty members have suspicion on author pays open access publishing model due to the potential conflict between publication fees and rigorous peer review. Bennett (2013) p.113-114 in eds. Shorley \& Jub (2013) stated,

"Business models will continue to adapt and open access will continue to be a large discussion on point both from publishing and a political perspectives. Gold OA has shown that it can be a viable business model and it will continue to develop especially with the help of some significant political and funding council mandates. For many publishers it will evolve alongside traditional subscription business 
models and provide another way to facilitate scholarly communication".

Considering the Directory of Open Access Journals (DOAJ); only 3064 journals use author-payee model and obtain an amount to publish their papers while 6370 journals do not charge authors (http://www.doaj.org).

\section{Growth of Open Access Repositories- Green Route}

Apart from open access journals and other publications; growth of digital repositories is evidence for the development of open access. Because, digital repositories such as archives and institutional repositories are also supported to open access. Registry of open access repository (ROAR) and open DOAR has listed the registered repositories in the world. University of Southampton, U.K. has developed the registry of open access repositories. ROAR collects details of repositories of all types and provides the user with a search interface to assist in search of sites/literature (http://roar.eprints.org/).

IR should be registered in ROAR. According to ROAR at March 2015, there are 3315 repositories have been registered. Among them Africa has 99, Asia has 647, Europe has 1355, North America has 809, Oceania has 98 and South America has 307.

Among the 647 repositories of Asia; Sri Lanka has only one been registered while India has 107, Malaysia 37, Nepal 03, Pakistan 03, Thailand 07 and Bangladesh 10. This indicates that though Sri Lanka has a growth trend in establishing IR since 2009, and there are 21 repositories have been successfully established, registered IR in Open ROAR is only one.

ROAR provides access to institutional repositories or institutional records. They give special consideration to theses and dissertations. They give more priorities to these unpublished materials such as theses and dissertations because research findings of young scholars also contribute considerably to social, economic, technical and sustainable development of nations, even though they are unpublished. 
OpenDOAR (http://www.opendoar.org/) is also developed by University of Nottingham, UK. The aim of openDOAR is to promote the development of open access by providing timely information about the growth and status of repositories throughout the world. Seven repositories of Sri Lanka has been registered here. This reviews repositories to determine the quality of the sites. Seven repositories of Sri Lanka have been registered here.

\section{Growth of Open Access Journals -Gold Route}

DOAJ is a platform launched by the University of Lund, Sweden. Objective of DOAJ is to increase visibility of scientific publications and through which enhance open access to scholarly information for research and development. This platform consists of 10237 journals and 1,843,333articles. 6096 journals are searchable by article level. 136 countries of the globe have contributed to enrich this directory in order to maximize the visibility of research papers to global researchers. Sri Lanka is also launched 13 journals openly accessible through DOAJ. Specific feature of this site is users can retrieve results; a collection of articles for a single hit from several journals like an aggregated commercial database.

\section{Benefits of Open Access}

Kiley (2013, in eds. Shorley \& Jub, 2013), divided the benefits of Open Access into major three divisions. Those are greater visibility, enhance research process and cost savings. Papers are accessed without any barrier as these are more visible through OA. The first and foremost advantage of OA is they reduce the barriers of accessing scholarly information especially to focus on new areas of research. Free online availability of research papers facilitates access in many ways. Freely available literature can be accessed by scientists and society quickly. Greater access to research output maximizes impact of research. In addition this minimizes redundancy and speed of scientific process.

OA increases the number of potential users of any given article thus increases the usage and citations. It is important to note that if an article is downloaded and read by another researcher that may be cited or may not be. However, Harnard (2006) stated that self-archiving has increased its citations by $50 \%$ or more. 
Benefits of OA adoption are identified in the following manner.

1. Original work enables access to all readers, researchers, research funders and followers

2. Visible the derivative works with proper acknowledgement to the author.

Though the benefits are streamlined as above, direct benefits and importance of OA are identified as follows;

- Supports transmission of knowledge among scientific communities

- Eliminate access and usage barriers

- Facilitate accessibility and enhance visibility

- Research findings are disseminated to policy makers for decision making and development

The main benefit is reaching a much larger audience than a researcher could reach with any priced publication which may be in print or online. Reaching a larger audience increases the impact, including citation count. Many studies confirm that $\mathrm{OA}$ articles are cited significantly more often (on the order of 50$300 \%$ more often) than non-OA articles from the same journal and year (http://opcit.eprints.org/oacitation-biblio.html).

OA facilitates the following.

- Helps funding bodies to evaluate the research they have funded

- Libraries are forced to cut subscriptions with inflating journal prices. This struggle has come to an end.

- To maximize and measure the uptake, usage applications and impact of research output of universities

- It shows permanent record of the research output of university

- Uplift the rank of the university based on webometric analysis

On the other hand most funding bodies, research institutions, universities, governmental bodies and ministries need to view the publications of the research they are financing. Therefore publishing in open access journals or archiving in institutional repositories is made mandates, globally. In addition to open access journals open text books a subset of OER also have impact on students' learning. Hilton et al. (2013) found that students save a potentially significant amount of money if the faculties recommend open text books. 


\section{Open Access Scholarly Publishing Mandates}

Jub (2013) in Eds. Shorley \& Jub (2013) described; around the world about 90 research funding bodies made OA as a condition for research grant that the research output should be made openly accessible. OA was mandated by many research funders. At first a research paper on 'Malaria Vaccines' was unable to access by the director of Well come Trust and demanded for $\$ 30$. But the research was funded by the particular funder together with Medical research Council, UK. Director of the funding body-Welcome Trust considered this matter seriously and got to know that medical practitioners, researchers, clinicians, patients and industry based personal unable to access the paper without subscription. Then in 2002, Welcome Trust announced Open Access Policy. This policy stated that all research papers that have been accepted for publications in a peer reviewed journal and are supported in whole or partially by the Welcome Trust funding must be made available through PubMed Central (PMC) and UK PubMed Central (UKPMC) as soon as possible and in any event within 06 months of the journal publisher's official date of final publications.

The OA policy of Welcome Trust has included three more elements in order to support the OA publications.

1. Provide additional charges for the grant holders to cover publication fee

2. When an OA fee is charged such works must be accessible under creative commons, attribution license [cc-By]

3. They affirmed that funding decision is made by considering the intrinsic merit of work and not for the journal in which it is published.

Following this OA mandates; research works carried out under public grant or any other research funds, request the grant recipient to provide the research papers openly accessible to other researchers. Some governments, research funders, learned societies and universities have mandated the grant recipient to deposit their research papers in IR or any other subject repositories or archives to make the research findings freely accessible to all. UK, USA and European Union are pioneers in this venture. Potential benefits of OA were realized by the research funders around the world. Pinfield (2013) carried out a research to analyze the attitudes and activities of UK medical research 
charities in relation to open access. His study resulted that majority medical research charities positively regarded OA as important and considered to support the cost and expenses to OA publication. Some of them consider funding for Article Processing Charge (APC) with annual research expenditures while some others do not. This study emphasizes how much the cost and expenses of OA publishing is important to ensure implementation of OA.

Eisenback (2006) requested scientists and granting agencies to invest money into article processing fees to cover the cost of OA publishing. He also suggested publishers who seek to increase impact factors of their journals to provide open access option. In addition he stated the funding or granting agencies to make mandate publishing papers in OA journals rather depositing in OA archives in order to disseminate the knowledge of scientific advancement.

\section{OA Mandate- UK}

As a consequence of the OA mandate of Welcome Trust in 2005 Research Council of UK (RCUK) was mandated Open Access. In 2006 RCUK requested the institutions of the research grantee to provide the publishing fee. But Medical Research Council (MRC) paid any levies charged by the publishers who offer OA options and they followed OA policy from 2006 onwards. Then Arthritis Research UK, Cancer Research UK and Myrovlytis Trust introduced OA policy in 2007 (Pinfield (2013). Biotechnology and Biological Sciences Research Council (BBSRC) mandated Open Access since 2008. The importance of making the scientific output freely accessible was highly realized all over the globe now. Finch Report was published in 2012 which awaken many research funders and institutions to follow OA policy. Following the finch Report RCUK also revised its policy by including the publishing fee. They award Block Grants to UK Higher Educational Institutions (HEIs), then neither researchers no the HEIs have to fund the publication fee, but RCUK. Following Research Council UK, Higher Education Funding Council, England has published their statement in 2012 and refined in 2013. This policy revision has accelerated the transition to OA in UK and beyond significantly. 


\section{OA mandate in Europe}

European Commission developed an OA policy in 2008. They mainly covered research papers of Health, Environmental Science and Energy. Then European Union mandated OA. This report says that

"Access to Scientific information, constitutes an essential element in accelerating the implementation of knowledge, fostering innovation and contributing to the quality of research" (European Commission,2007; Houghton et al,2009)

European Commission adopted a new OA policy in 2012, (Pinfield (2013).

\section{OA mandate in USA}

National Institute of Health (NIH) formulated a draft proposal in 2004 to be mandated OA. This proposal indicated that all funded research of NIH should be made openly available through Pub Med Central after six months of publication. NIH updated the proposal in 2005 and the policy relaxed the restriction of 6 months. House of Representatives has developed the Federal Research Public Access Act in 2012. Federal Fair Access to Science and Technology Research (FASTR) announced OA bill in February 2013. Office of Science and Technology Policy (OSTP) also published OA policy memorandum in the same period. As a consequence many institutions and universities have now mandated open access.

\section{OA Mandate in Australia}

Australian Research Council (ARC) introduced OA policy in 2013 and the National Health and Medical Research Council (NHMRC) mandated OA publishing of the research funded by them.

Their objective is publications created by the research work carried out by the fund provided by them should be widely accessible by other researchers and all other communities as well in the world and that they should earn maximum impact.

\section{OA in India}

Department of Biotechnology (DBT) and Department of Science and Technology (DST) under the Ministry of Science and Technology had announced jointly the Open Access Policy on 12th December 2014. This policy emphasized that 'information and knowledge generated through the use 
of these funds are made publicly available as soon as possible" within the context of Indian law and Intellectual property policy of India.

Some governments have the policy that publicly funded research should be freely accessible in the public domain. At present there are many institutions and universities research funders have mandated open access for the research carried out by using public funds, for instance, South Africa also advances in establishing open access policy (Denise 2015).

There are more than hundreds of research funders have mandated, and this emphasizes the importance of open access. Considering Sri Lanka; National Science Foundation has done several initiatives related to the development of open access. Those are national workshops, awareness progrmmes, financially and technically supporting local libraries to establish institutional repositories, national digitization project and national e-repositories, etc. (Perera, 2013). In addition, they have developed an open access policy and requested the universities and other research institutions to follow it to create their own policy. We, the Sri Lankans also in par with other countries in the globe and also should realize the importance of open access to achieve advancement in research and development.

\section{Summary}

Open access introduces new opportunities and earn higher impacts. Open access has tremendously grown in a decade. The growth seems not evolutionary but revolutionary. Open access scholarly publishing mandates showcase the paradigm shift in scholarly communication practices. Where are we, the Sri Lankans in this movement? Though we have initiated institutional repositories, and publishing open access journals, poor participation in worldwide trend indicates that there are rooms for improvement. Lack of literature in open access research studies regarding the status of Sri Lanka also should be noted. This study recommends it is crucial to conduct a more indepth study regarding Sri Lanka's status in the global OA movement. Perceptions and attitudes of academics, researchers, librarians and policy makers towards open access also need to be studied and island wide advocacy programmes should be conducted. While the other countries in the world are 
marching forward with research data management, open data and open research aspects of open science, we are still at the infant level. A need has arisen for mindset change of our researchers. Will the paradigm shift of scholarly publishing be mandated in Sri Lanka, too by implementing open access policy? May this lead higher research productivity in future?

\section{References}

Bennett, R. (2013). The changing role of the publisher in the scholarly communications process. In D. Shorley \& M.Jubb (Eds.), The Future of Scholarly Communication (pp.103 -114). London: Facet Publishing.

Bethesda Statement on Open Access Publishing (2003). Retrieved from http://legacy.earlham.edu/ peters/fos/bethesda.htm (Accessed on 07th Oct.2013)

Brown, M. L. (2013). The role of the research library. In D. Shorley \& M. Jubb, (Eds.), The Future of Scholarly Communication (pp. 157 168). London: Facet Publishing.

Budapset Open Access Initiatives (2003). Retrieved from http://www.budapestopenaccessinitiative.org/read (Accessed on 07th Oct.2013)

Eugenio, P. (2003). Academic staff use, perception and expectations about open access archives: a survey of Social Science Sectorat Bresica University. Retrieved from http://eprints.rclis.org/4408/

European Commission (2015). Open Science- open access. Retrieved from http://ec.europa.eu/programmes/horizon\%2020-section/open-scienceopenaccess (Accessed on 08th October, 2015)

European commission, (2015). Final report, Consultation-Science 2.0. Retrieved from http://ec.europa.eu/research/consultation/science2.0/science_2_0_final_report,pdf (Accessed on $08^{\text {th }}$ October 2015) Eysenbach, G. (2006). Citation advantage of open access articles. PLoS BIOLOGY, 4(5). doi: 10.1371/journal.pbio.0040157. (Accessed on 05th of October, 2015)

Fidishun, D. (2010). The paradigm shift in scholarly communication: will publications perish? Retrieved from http://www.personal.psu.edu/ dxf19/blogs/dolores_list_of_cfps/2010/03/the-paradigm-shift-inscholarly-communication-will-publications-perish.html (Accessed on 28 February, 2014).

Fernandez, R.C. (2013). The Landscape of Open Access Journals in Cuba: the strategy and model for its development. In L. M. Rudasill, \& M. 
E. Dorth-Duque (Eds.), Open Access and Digital Libraries (pp.89 111). Berlin: De Gruyter Saur

Finch Report (2012). Accessibility, sustainability, excellence: how to expand access to research publications. Report of the Working Group on Expanding Access to Published Research Findings. Retrieved from http://www.researchinfonet.org/wp-content/uploads/2012/06/FinchGroup-report-FINAL-VERSION.pdf (Accessed on 02nd February, 2015)

Halliday, L. (2001). Scholarly communication, scholarly publication and the status of emerging formats. Information research, 6 (4), Retrieved from http://InformationR.net/ir/ paper111.html (Accessed on 09th March,2014)

Harley, D. (2013). Scientific Communication: Cultural Contexts, Evolving Models. Science, 342 (6154), 80-82. doi:10.1126/SCIENCE. 1243622

Harnad, S. (2004). Comparing the Impact of Open Access (OA) vs. Non-OA Articles in the Same Journals. D- Lib Magazine, 10 (6)

Hilton, J.L et al. (2013). The Adoption of Open Educational Resources by one community college math department. The International Review of Research in Open and Distance Learning, 14 (04)

IFLA statement for Open Access to scholarly literature and research documentation, Retrieved from http://www.ifla.org/publications/iflastatement-on-open-access-to-scholarly-literature-and- researchdocumentation (Accessed on 07th of October)

Islam, A. Md. \& Akter, R. (2013). Institutional Repositories and Open Access Initiatives in Bangladesh: A New Paradigm of Scholarly Communication. Liber Quarterly, 23 (1), 3-24

Kenneway, M. (2011), Author attitudes towards open access publishing. Communication on behalf of INTECH Open Access Publisher, Retrieved from http://www.intechopen.com/public_files/Intech_ OA_Apr11.pdf

Kiley, R. (2013). The view of the research funder. In D. Shorley \& M. Jubb (Eds.), The Future of Scholarly Communication (pp. 131 -144).

London: Facet Publishing.

Koler-Povh, T., Turk, G., and Juznic, P. (2012). Does the Open Access Business Model Have a Significant Impact on the Citation of Publications? Case Study in the Field of Civil Engineering. In Proceeding of the 5th Belgrade International Open Access Conference, pp.89-90. Retrieved from http://boac.Ceon.rs/index.php/ BOAC/paper/view/86/8 
Lancaster, F.W. (1991). Bibliometric methods in assessing productivity and impact of research, Sarada Ranganathan Endowement for Library and Information Science, Bangalore.

Lawrence, S. (2011). Free online availability substantially increases a paper's impact, Retrieved from http://www.nature.com

Mayer, K. (2015). From Science 2.0 to open Science:turning rhetoric into action. Retrieved from http://www.researchgate.net/publication/ 279450025

Park, J. \& Qin, J. (2007). Exploring the Willingness of Scholars to Accept Open Access: a grounded theory approach. Journal of Scholarly Publishing, 38(2), 55 -84. doi:10.1353/scp.2007.0009

Perera, S. (2013). Open Access Initiatives of the National Science Foundation, 4th COAR Annual meeting, Istanbul, Turkey, Presentation. Retrieved from https://www.coar-repositories.org/ files/1_Sri-Lanka-NSF.pdf (Accessed on 09 January, 2015)

Pinfield, S. (2009). Journals and Repositories: an evolving relationship, Learned Publishing 22(3), 165-175. doi:10.1087 2009/302

Pinfield, S. (2013). Is scholarly publishing going from crisis to crisis. Learned Publishing, 26(2), 85-88. Retrieved from http://eprints. whiterose.ac.uk/ (Accessed on 05th of February, 2015)

Prosser, D. C. (2003). From here to there: a proposed mechanism for transforming journals from closed to open access. Learned Publishing, 16 (3), 163-166

Sawant, S. (2012). Past and present scenario of open access movement in India. The Journal of Academic Librarianship, 39(1). Retrieved from http://www.sciencedirect.com/science/article/pii/S009913331200 1759 (Accessed on 12th, Nov.2014)

Suber, P. (2004). A very brief introduction to open access. Retrieved from http://www.earlham.edu/ peters/hometoc.htm

Swan, A. (2012). Policy guidelines for the development and promotion of open access, UNESCO

McGrath, M. (2013). The changing role of the journal editor. In D.Shorley \& M. Jubb (Eds.), The Future of Scholarly Communication (pp. 117 -129). London: Facet Publishing. 